University of Wollongong

Research Online

Australian Institute for Innovative Materials -

Papers

Australian Institute for Innovative Materials

$1-1-2018$

\title{
A "Tandem" Strategy to Fabricate Flexible Graphene/Polypyrrole Nanofiber Film Using the Surfactant-Exfoliated Graphene for Supercapacitors
}

Kewei Shu

University of Wollongong, kewei@uow.edu.au

Yunfeng Chao

University of Wollongong, yc682@uowmail.edu.au

Shulei Chou

University of Wollongong, shulei@uow.edu.au

Caiyun Wang

University of Wollongong, caiyun@uow.edu.au

Tian Zheng

University of Wollongong, tz648@uowmail.edu.au

See next page for additional authors

Follow this and additional works at: https://ro.uow.edu.au/aiimpapers

Part of the Engineering Commons, and the Physical Sciences and Mathematics Commons

Research Online is the open access institutional repository for the University of Wollongong. For further information contact the UOW Library: research-pubs@uow.edu.au 


\title{
A "Tandem" Strategy to Fabricate Flexible Graphene/Polypyrrole Nanofiber Film Using the Surfactant-Exfoliated Graphene for Supercapacitors
}

\author{
Abstract \\ The surfactant-assisted liquid-phase exfoliation of expanded graphite can produce graphene sheets in \\ large quantities with minimal defects. However, it is difficult to completely remove the surfactant from the \\ final product, thus affecting the electrochemical properties of the produced graphene. In this article, a \\ novel approach to fabricate flexible graphene/polypyrrole film was developed: using surfactant \\ cetyltrimethylammonium bromide as a template for growth of polypyrrole nanofibers (PPyNFs) instead of \\ removal after the exfoliation process; followed by a simple filtration method. The introduction of PPyNF \\ not only increases the electrochemical performance, but also ensures flexibility. This composite film \\ electrode offers a capacitance up to $161 \mathrm{~F} \mathrm{~g}-1$ along with a capacitance retention rate of over $80 \%$ after \\ 5000 cycles \\ Disciplines \\ Engineering | Physical Sciences and Mathematics

\section{Publication Details} \\ Shu, K., Chao, Y., Chou, S., Wang, C., Zheng, T., Gambhir, S. \& Wallace, G. G. (2018). A "Tandem" Strategy to \\ Fabricate Flexible Graphene/Polypyrrole Nanofiber Film Using the Surfactant-Exfoliated Graphene for \\ Supercapacitors. ACS Applied Materials and Interfaces, 10 (26), 22031-22041.

\section{Authors} \\ Kewei Shu, Yunfeng Chao, Shulei Chou, Caiyun Wang, Tian Zheng, Sanjeev Gambhir, and Gordon G. \\ Wallace
}




\section{A "Tandem" Strategy to Fabricate Flexible}

Graphene/Polypyrrole Nanofiber Film Using the Surfactant-Exfoliated

Graphene

for

\section{Supercapacitors}

Kewei Shu ${ }^{1}$, Yunfeng Chao ${ }^{1}$, Shulei Chou ${ }^{2}$, Caiyun Wang $^{1 *}$, Tian Zheng ${ }^{l}$, Sanjeev Gambhir ${ }^{1}$, Gordon G. Wallace ${ }^{1}$

1 Intelligent Polymer Research Institute, ARC Centre of Excellence for Electromaterials Science, AIIM Facility, Innovation Campus, University of Wollongong, Wollongong, NSW 2522 Australia.

2. Institute for Superconducting \& Electronic Materials, AIIM Facility, Innovation Campus, University of Wollongong, Wollongong, NSW 2522 Australia.

* Corresponding author. Tel: +61 2 42981426. Fax: +61 24298 1499. E-mail address: caiyun@uow.edu.au (C.W.).

KEYWORDS: Graphene; Surfactant Assisted Liquid Exfoliation; Polypyrrole Nanofibers; Supercapacitor; Flexible Electrode. 
ABSTRACT The surfactant assisted liquid phase exfoliation of expanded graphite can produce graphene sheets in large quantities with minimal defects. However, it is difficult to completely remove the surfactant from the final product, thus affecting the electrochemical properties of the produced graphene. In this article, a novel approach to fabricate flexible graphene-PPy film was developed: using surfactant cetyltrimethylammonium bromide (CTAB) as a template for growth of polypyrrole nanofibers (PPyNF) instead of removal after the exfoliation process; followed by a simple filtration method. The introduction of PPyNF not only increases the electrochemical performance but also ensures flexibility. This composite film electrode offers a capacitance up to $161 \mathrm{~F} \mathrm{~g}^{-1}$ along with a capacitance retention rate of over $80 \%$ after 5,000 cycles.

\section{INTRODUCTION}

The emerging novel 2D nanocarbon materials, graphene, has attracted significant attention in both theoretical and experimental research communities ${ }^{1-2}$. Its superior electrical conductivity, large surface area and high chemical stability render it a promising material for energy storage. It has demonstrated excellent electrochemical properties in batteries or supercapacitors $^{3-4}$. The growing market for flexible electronics, such as flexible displays ${ }^{5}$, bendable smart phones, electronic skins ${ }^{6}$ and implantable medical devices ${ }^{7}$, requires the development of flexible power sources ${ }^{8-9}$ and consequently flexible electrodes. The unique structure of graphene sheets, two-dimension with a high aspect ratio, facilitates the fabrication of robust freestanding films for direct use as flexible electrodes eliminating the dead weight or volume from current collectors or additives used in common electrodes ${ }^{10-11}$.

Among various graphene synthesis routes, wet chemical exfoliation is a realistic approach to realize mass production. Commonly used wet chemical method is exfoliation of oxidized graphite oxide with a subsequent reduction process ${ }^{12-13}$. The resultant graphene nanosheets normally contain a considerable number of defects. Also, toxic reagents are used in this time- 
consuming preparation procedure. It is highly desirable to develop methods to prepare graphene using mild condition to minimize defects.

Graphene nanosheets can be produced by liquid-phase exfoliation (LPE) of graphite (i.e., natural graphite, highly oriented pyrolytic graphite (HOPG) or expanded graphite) using organic solvent or aqueous solution containing surfactant ${ }^{14-15}$. Expanded graphite, which can be massively produced by thermal treatment of commercially available expandable graphite

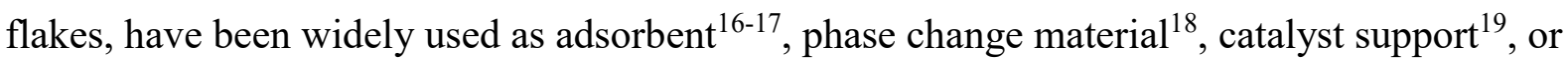
battery electrodes ${ }^{20}$. It is a suitable starting material for exfoliation due to its pre-expanded structures $^{21}$. It has been successfully exfoliated in aqueous solution with rose Bengal (serving as a surfactant $)^{22}$, in organic solvents with or without stabilizer ${ }^{23-24}$. However, the surfactant adsorbed on the graphene sheets is difficult to be removed, resulting in decreased conductivity of graphene and deteriorated electrochemical performance. The surfactant may be used as dopant or template for growth of conducting polymer structures such as polypyrrole nanofiber. The incorporation of polypyrrole nanofiber (PPyNF) into graphene can not only provide large pseudocapacitance, but also reinforces the mechanical properties of the electrode produced ${ }^{25}$. PPyNF has demonstrated excellent performances in supercapacitors, lithium-ion batteries and biocompatible batteries ${ }^{26-29}$. However, PPyNF normally suffer from poor cycle life due to the physical changes accompanied with the doping/undoping of ions. The incorporation of carbon-based material can provide mechanical reinforcement that accommodates the volumetric changes and improve the electronic contact between polypyrrole nanostructures as well, leading to improved rate and cycle performance. $^{25,30}$

In this work, the cationic surfactant cetyltrimethylammonium bromide (CTAB) was used to exfoliate expanded graphite and then used as a template for the growth of nanostructured PPyNF. This approach can effectively utilize the surfactant, minimizing its negative effects 
on the electrode's electrochemical properties and enhances the flexibility. The demonstrated specific capacitance up to $160 \mathrm{~F} \mathrm{~g}^{-1}$ at $0.5 \mathrm{~A} \mathrm{~g}^{-1}$ and $128 \mathrm{~F} \mathrm{~g}^{-1}$ at $8 \mathrm{~A} \mathrm{~g}^{-1}$ indicates an excellent performance of the prepared graphene/PPyNF film.

\section{EXPERIMENTAL}

2.1 Exfoliation of worm-like expanded graphite

Expandable graphite flakes (3772, Asbury Graphite Mills USA) was thermally expanded at $500{ }^{\circ} \mathrm{C}$ for $15 \mathrm{~s}$ to obtain worm-like expanded graphite under argon. The exfoliation of expanded graphite in the presence of surfactant cetyltrimethylammonium bromide (CTAB) produced exfoliated graphene and was denoted as graphene for short in this work. Briefly, expanded graphite was dispersed into CTAB aqueous solution $\left(1 \mathrm{mg} \mathrm{mL}^{-1}\right)$ to give a $10 \mathrm{mg}$ $\mathrm{mL}^{-1}$ dispersion, then being ultrasonicated for $4 \mathrm{~h}$ with $60 \%$ amplitude (Branson Digital Sonifier). The supernatant was collected after centrifugation at $4400 \mathrm{rpm}$ for $40 \mathrm{~min}$. The sediment left can be recycled and reused. The mass of graphene in the dispersion was confirmed by collecting it on a polycarbonate filter membrane. The absorption coefficient $\alpha$ of graphene dispersion was determined from the calibration curve obtained using the UV absorbance at $660 \mathrm{~nm}^{15}$.

\subsection{Preparation of graphene-PPyNF film}

The formed graphene/CTAB dispersion was directly used to prepare graphene-PPyNF film. Pyrrole monomer and concentrated hydrochloric acid (to give a $0.2 \mathrm{M} \mathrm{HCl}$ concentration) were added into this dispersion, followed by slow addition of oxidant ammonium persulfate (APS) (APS: Py $=2: 1$, by weight). The reaction was kept in an ice-water bath under stirring for $6 \mathrm{~h}$. The resultant dispersion was filtrated forming a flexible graphene-PPyNF film, then washed thoroughly by water and ethanol to remove the impurities. The total weight of graphene and pyrrole monomer was controlled at the constant $(\sim 36 \mathrm{mg})$. The pure PPy fibre film (PPyNF) and neat graphene film was also prepared for comparison. Since the neat 
graphene film cannot be peeled off from the filter membrane, and a rGO paper was prepared using the graphene from graphite oxide route ${ }^{31}$.

\subsection{Characterization}

Dimension and thickness of graphene sheets were characterized by atomic force microscope (AFM, Asylum MFP). A scanning electron microscope (SEM, JEOL JSM7500FA) was used to investigate the surface and cross-sectional morphology. Raman spectra were performed on a Raman spectrometer (Jobin Yvon HR800, Horiba) utilizing a $632.8 \mathrm{~nm}$ laser. X-ray photoelectron spectroscopy (XPS) was measured using an Energy Analyzer (PHOIBOS 100/150). The thermogravimetric analysis (TGA, Q500 TA instruments) was used to study the thermal stability (nitrogen atmosphere, $5^{\circ} \mathrm{C} \mathrm{min}^{-1}$ ramp rate). The bending test was conducted using a Shimadzu EZ mechanical tester, by repeatedly bent to an angle of $180^{\circ}\left(3 \mathrm{~mm} \mathrm{~s}^{-1}\right.$ cross-head speed $)$ for up to 5,000 cycles.

Flexible film electrodes were assembled into a symmetric supercapacitor (two electrode Swagelok-type cell, X2 Labwares Pty Ltd.) using $1 \mathrm{M} \mathrm{Li}_{2} \mathrm{SO}_{4}$ as electrolyte. A CHI 650D potentiostat ( $\mathrm{CH}$ Instruments, Inc.) was used to acquire the cyclic voltammetric data between 0.0 to $1.0 \mathrm{~V}$ at various rates. Charge/discharge tests were performed using a BTS300 battery test system (Neware Electronic Co.) between 0.005 to $1.0 \mathrm{~V}$. Electrochemical impedance spectra (EIS) were recorded by a Gamry EIS 3000 system, with frequency ranging from 0.01 $\mathrm{Hz}$ to $100 \mathrm{kHz}(10 \mathrm{mV}$ amplitude) at open circuit potential.

\section{RESULTS AND DISCUSSION}

3.1 Exfoliation of worm-like expanded graphite

Expanded graphite can be further expanded over 80 times by thermal treatment ${ }^{32}$. It presents a typical worm-like structure composed of parallel sheets separated by pores of several micrometer dimensions (Figure 1a). The pore wall thickness is $\sim 80 \mathrm{~nm}$, indicating 
that it consists of multiple layers of graphene sheets (Figure $1 \mathrm{~b}$ inset). Such an expanded structure is an excellent precursor to complete exfoliation ${ }^{33}$. After liquid-phase exfoliation (as per the Experimental Section), transparent and wrinkled graphene sheets can be found via the transmission electron detector of SEM (TED-SEM) (Figure 1c). The successful exfoliation of expanded graphite was further confirmed by AFM. Figure 1d is the AFM image of graphene on a $1.5 \times 1.5 \mu \mathrm{m}$ surface of silicon wafer. Images revealed single flakes $\sim 200-400 \mathrm{~nm}$ in dimension and $\sim 4-5 \mathrm{~nm}$ in height. The apparent height of graphene derived from wet chemical method is reported to be $\sim 1.2 \mathrm{~nm}$ as measured by $\mathrm{AFM}^{13}$. It suggests that graphene obtained in this work consists of $\sim 3-4$ layers. 

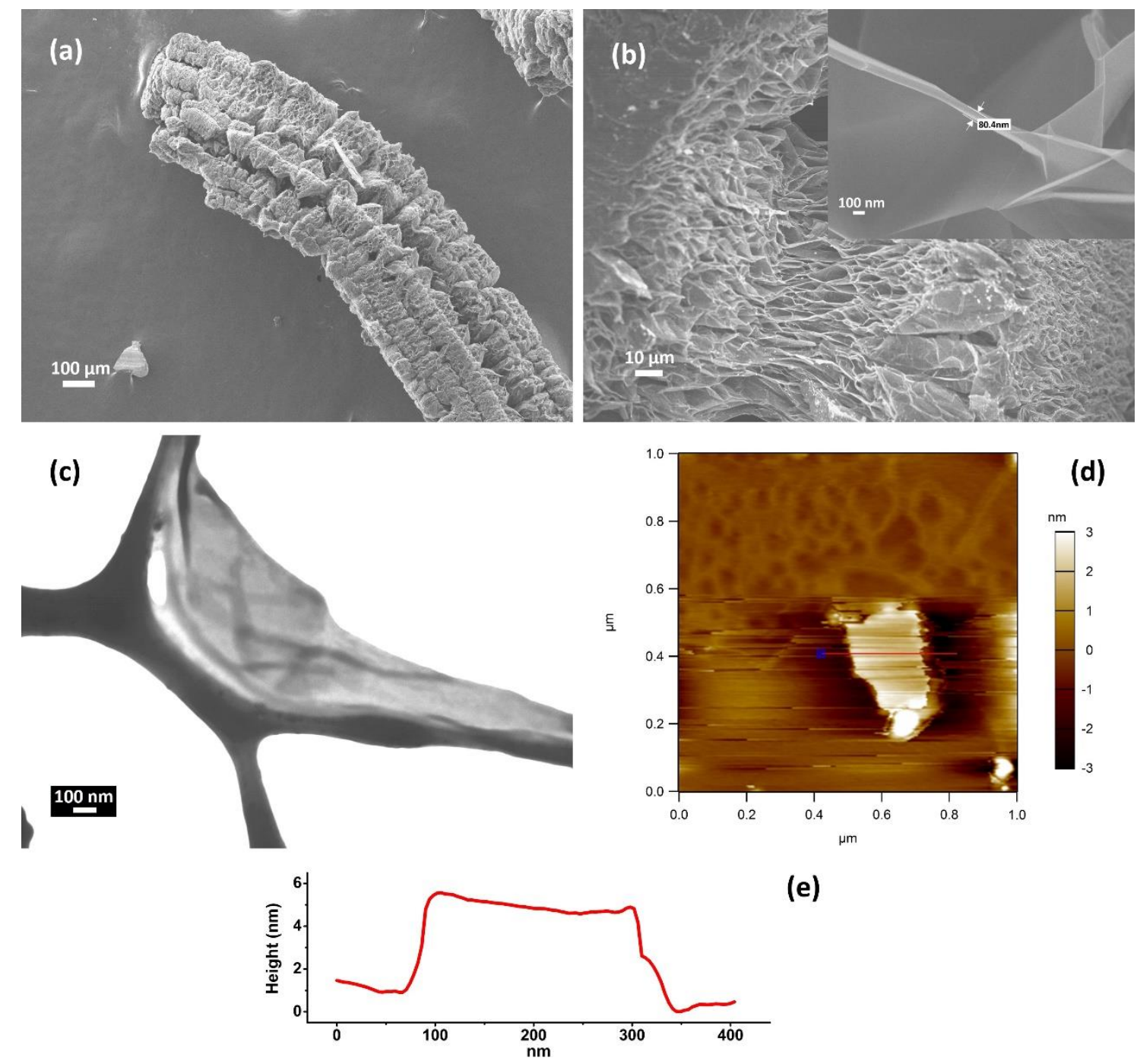

(e)

Figure 1. SEM images of expanded graphite (a-b); TED-SEM images of graphene (c); AFM image (d) and height profile (e) of graphene.

Figure 2 shows the Raman spectra of expanded graphite and graphene. The chemically reduced graphene oxide (rGO) paper prepared via graphite oxide exfoliation route is also shown for comparison. The three main peaks for graphite-like materials are D band, G band and $2 \mathrm{D}$ band. ${ }^{34}$ The $\mathrm{G}$ band refers to the first order scattering of E2g mode; D band is related to the first order of zone-boundary phonons which reflects the structural defects of graphite materials; and 2D band is the second order of zone-boundary phonons, which can be used to distinguish single, double, few and multi-layered graphene structure. ${ }^{35-36}$ The expanded graphite and graphene display a prominent $\mathrm{G}$ band at $1581 \mathrm{~cm}^{-1}$, similar to natural graphite 
powder. A weak D band at ca. $1333 \mathrm{~cm}^{-1}$ for expanded graphite is probably attributed to the structure defects produced during the intercalation and expansion process. Graphene displays a much stronger D band at $1333 \mathrm{~cm}^{-1}$, indicating that more defects were created. For rGO, the strong D band indicates large amounts of disorder formed during oxidation, exfoliation and reduction ${ }^{13}$. The $2 \mathrm{D}$ peak in expanded graphite appears at around $2700 \mathrm{~cm}^{-1}$. It can be split into two peaks at 2670 and $2694 \mathrm{~cm}^{-1}$, similar to that of bulk graphite, indicating a multilayered graphene structure. Graphene presents a broader 2D peak, and an increased intensity of the peak at $2666 \mathrm{~cm}^{-1}$ yet still slightly weaker than the peak at higher frequency. It is the characteristic feature of thin flakes composed of a few graphene layers (typically $2 \sim 5$ layers $)^{15,36-37}$, which agrees well with the reported CTAB stabilized exfoliated graphene ${ }^{38}$. A broad, down-shifted 2D single peak with lower intensity was observed for $\mathrm{rGO}$, which is caused by the steric effects of oxygen moieties, partial amorphization and reduced $\mathrm{sp} 2$ domains $^{39-40}$.

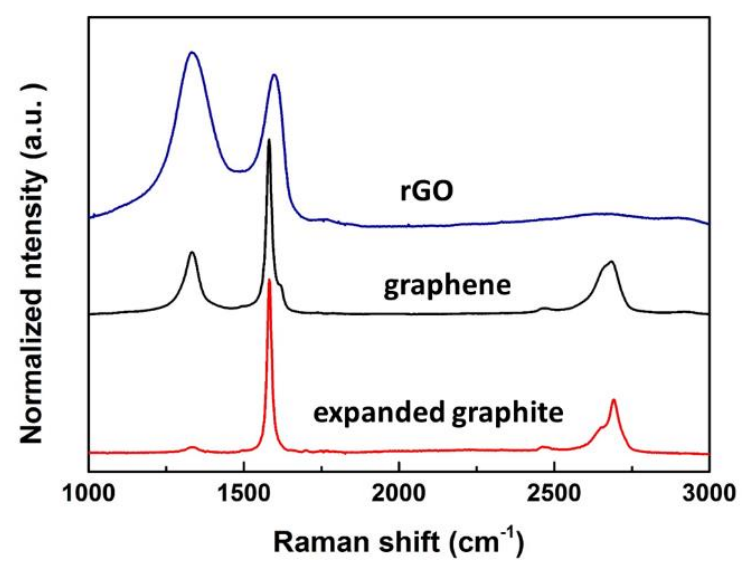

Figure 2. Raman spectra of rGO, graphene and expanded graphite.

\subsection{Synthesis and physicochemical characterization of G-PPyNF film}

The graphene/CTAB dispersion from the exfoliation process was directly used to synthesize G-PPyNF via an in situ chemical polymerization (Figure 3). The product exfoliated graphene nanosheets and the remained CTAB were used as reactants in the next 
stage: growth of polypyrrole nanofiber and concomitant formation of PPyNF/graphene composite. We described such a process as a "tandem" strategy due to its similar features as "tandem reaction" in organic chemistry: a consecutive reaction that each subsequent reaction occurs using intermediates/chemical functionalities formed in the previous step. ${ }^{41}$ The surfactant $\mathrm{CTAB}$ confined the formation and growth of PPyNF as a template. Hydrophobic pyrrole monomer seated on the hydrophobic tail and was encapsulated in the interior of CTAB micelles. The addition of oxidant APS initiated the polymerization, and the growth of PPy proceeded forming nanowires/nanofibers. ${ }^{42}$ The CTAB was converted into $(\mathrm{CTA})_{2} \mathrm{~S}_{2} \mathrm{O}_{8}$ in the initial stage, and then reduced to $(\mathrm{CTA})_{2} \mathrm{SO}_{4}$ after completion of polymerization. ${ }^{42} \mathrm{~A}$ flexible graphene/polypyrrole nanofiber film was then produced through vacuum filtration of such solution. The $\mathrm{CTA}^{+}$containing residue could be easily removed by thoroughly washing with water and ethanol. ${ }^{43-44}$ These films are named as G-PPyNF1 and G-PPyNF2, according the weight ratio of graphene to pyrrole $(1: 4$; or $1: 8)$. Composite films with a higher graphene ratio (e.g. 1:1, 1:2) were fragile and crumbled into powders (inset of Figure 4a), making them unsuitable for us as flexible electrode. The neat graphene film consisted of stacked graphene sheets but without a clear layered structure. Its thickness was $\sim 10 \mu \mathrm{m}$ (Figure $4 \mathrm{~b}, \mathrm{c}$ ). This film was not robust, which can be ascribed to the poor interaction between graphene sheets owing to the lack of functional groups. The incorporation of PPyNF can bind and entangle graphene sheets to enhance the mechanical properties. However, the composite with more content of PPyNF may suffer from poor rate and cycle performance. 


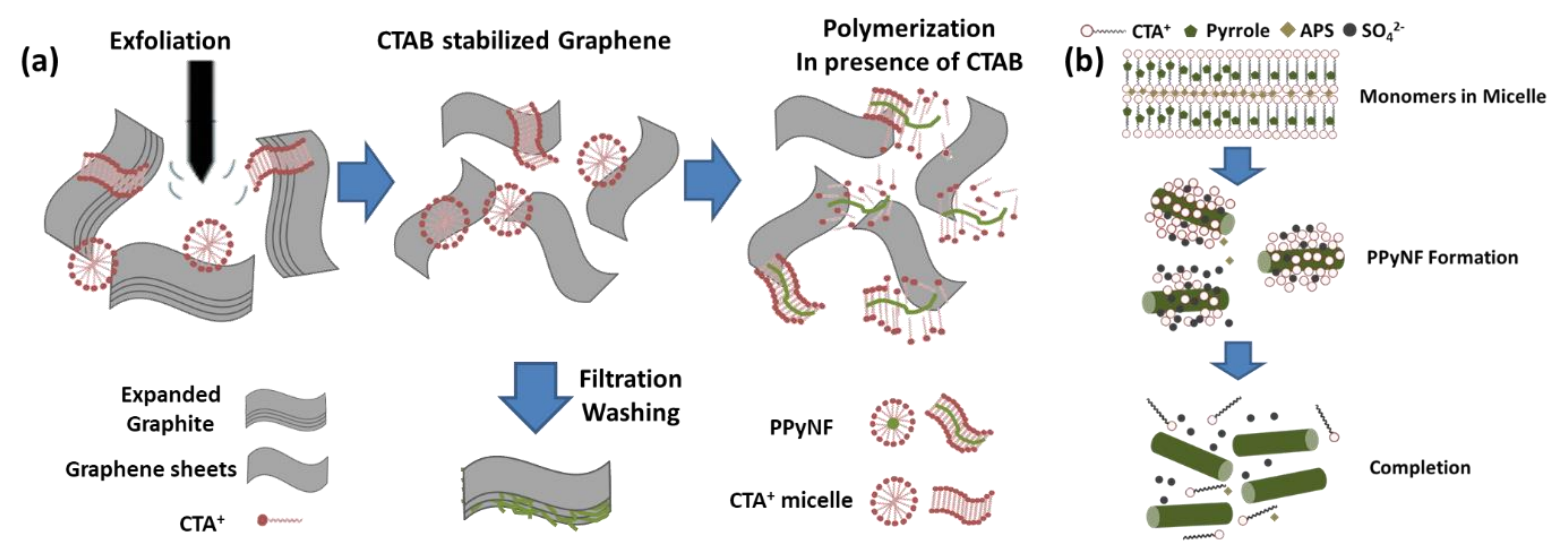

Figure 3. Schematic illustration of fabrication procedure of G-PPyNF film (a) and formation of PPyNF (b).

As revealed by the cross-section image, PPyNF film consists of entangled PPy nanofibers, with thickness of around $30 \mu \mathrm{m}$ (Figure 4d, e). These nanofibers can be clearly evidenced from the surface morphology of the film (Figure 4f). In G-PPyNF film, PPyNF is sandwiched between graphene sheets due to the interaction between PPy and the graphene aromatic basal (Figure 4g, j). The graphene sheets were bound by nanofibers (Figure 4i, 1), thus ensured the flexibility of the hybrid paper. 


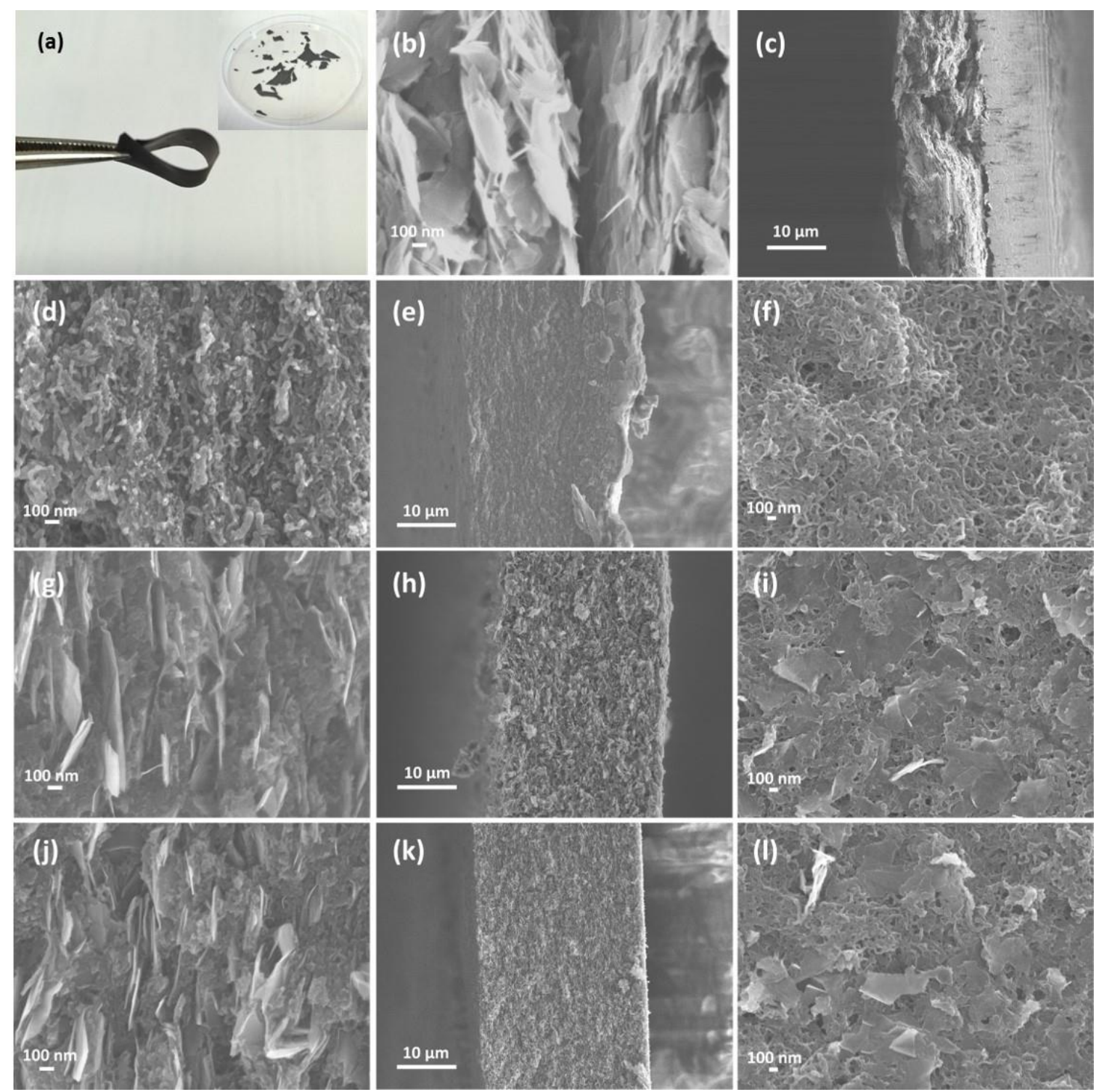

Figure 4. Digital image of G-PPyNF1 flexible film (a) (inset: film with a graphene:pyrrole ratio of 1:2). Cross-sectional view of graphene film on filter membrane (b, c), PPyNF film (d, e), G-PPyNF1 film (g, h) and G-PPyNF2 film (j, k); Surface morphology of PPyNF film (f), G-PPyNF1 film (i) and G-PPyNF2 film (1).

PPyNF, graphene, G-PPyNF1 and G-PPyNF2 films were studied by Raman spectroscopy (Figure 5a-e). PPyNF film displayed two characteristic peaks at $1345 \mathrm{~cm}^{-1}$ and $1539 \mathrm{~cm}^{-1}$, attributed to the $\pi$-conjugated planar structure and ring stretching of the polypyrrole backbone respectively ${ }^{45}$. Tiny peaks near 940 and $975 \mathrm{~cm}^{-1}$ can be assigned to the quinoid polaronic and bipolaronic structure ${ }^{26}$. Three main peaks for graphene, D peak, G peak, 2D peak 
appeared at $1333 \mathrm{~cm}^{-1}, 1581 \mathrm{~cm}^{-1}$ and $2700 \mathrm{~cm}^{-1}$. For G-PPyNF hybrid films, the D and G band overlapped with those two dominant peaks of PPyNF, and became broader. The 2D peak became decreased in intensity with decreased graphene content. These changes can be attributed to the interactions between graphene and PPyNF.

Figure 5f shows the TGA curves obtained for graphene, PPyNF and G-PPyNF films. A weight loss of $\sim 3 \%$ over $150-200^{\circ} \mathrm{C}$ for graphene may be ascribed to the pyrolysis of residual oxygen-containing groups. This loss can be hardly observed in G-PPyNF films owing to the relatively low content of graphene. Similar to other reported PPy doped with $\mathrm{SO}_{4}{ }^{2-}$ or PPy using CTAB template (actually doped with $\mathrm{SO}_{4}{ }^{2-}$ as well), the thermal degradation began at $\sim 210^{\circ} \mathrm{C}$ and the maximum rate of decomposition started from about $250^{\circ} \mathrm{C}$. ${ }^{46-48}$. The total weight loss over the temperature range of room temperature to $600{ }^{\circ} \mathrm{C}$ for graphene, GPPyNF1, G-PPyNF2 and PPyNF was 10\%, 32\%, 43\% and 55\%. 

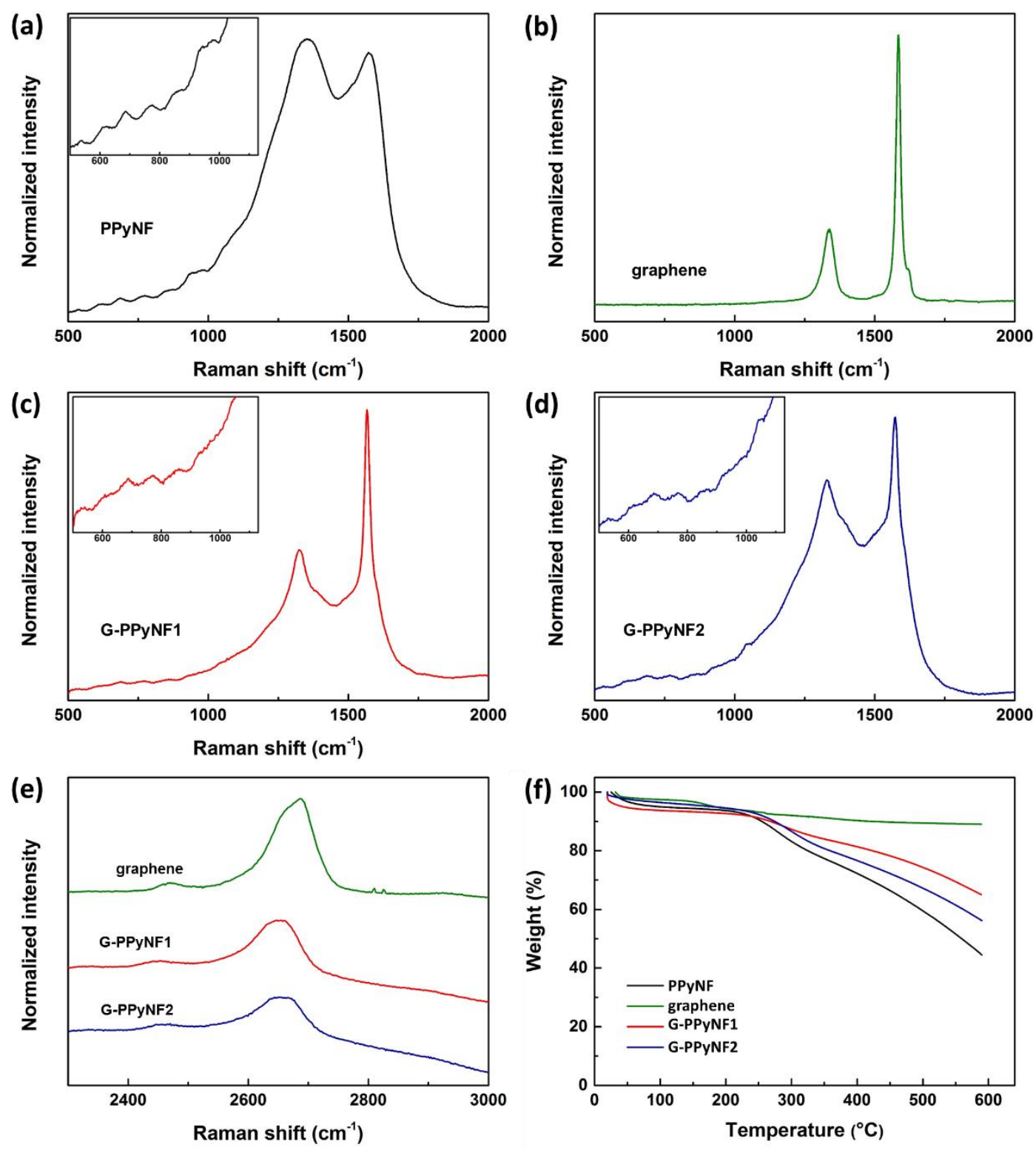

Figure 5. Raman spectra of PPyNF (a), graphene (b), G-PPyNF1 (c), G-PPyNF2 (d); and 2D peak of graphene, G-PPyNF1 and G-PPyNF2 (e). TGA curves of PPyNF, graphene, GPPyNF1 and G-PPyNF2 film (f). (Insets in a, c and d: Raman spectra between 500-1200 $\mathrm{cm}^{-}$ $\left.{ }^{1}\right)$. 


\subsection{Electrochemical performance of G-PPyNF film}

PPyNF film showed a quasi-rectangular cyclic voltammetry $(\mathrm{CV})$ curves at a low scan rate of $20 \mathrm{mV} \mathrm{s}^{-1}$ (Figure 6a). It became distorted with the increasing scan rate. When increased to $400 \mathrm{mV} \mathrm{s}^{-1}$, highly distorted leaf-shaped CV was presented indicating the limited ionic and electronic transport in bulk PPyNF film. Neat graphene film electrode presented an electrical double layer (EDL) capacitance feature maintaining the rectangular-shaped curves even at $400 \mathrm{mV} \mathrm{s}^{-1}$ due to the high conductivity but yielding much lower current response compared to G-PPyNF composite films. With the incorporation of graphene, the capacitive performance of G-PPyNF composite film was significantly improved at high scan rates. The G-PPyNF1 film can maintain a near-rectangular curve at $400 \mathrm{mV} \mathrm{s}^{-1}$, while G-PPyNF2 with lower graphene ratio presented a distorted $\mathrm{CV}$ shape at such high scan rate. At $20 \mathrm{mV} \mathrm{s}^{-1}$, the PPyNF, graphene, G-PPyNF1 and G-PPyNF2 film presented a capacitance of 170, 21, 120, $148 \mathrm{~F} \mathrm{~g} \mathrm{~g}^{-1}$, respectively. When a higher scan rate of $400 \mathrm{mV} \mathrm{s}^{-1}$ was applied, the respective capacitance retention was $23 \%, 76 \%, 65 \%$ and $47 \%$. Clearly the rate performance of hybrid film was improved with the increasing graphene ratio. 

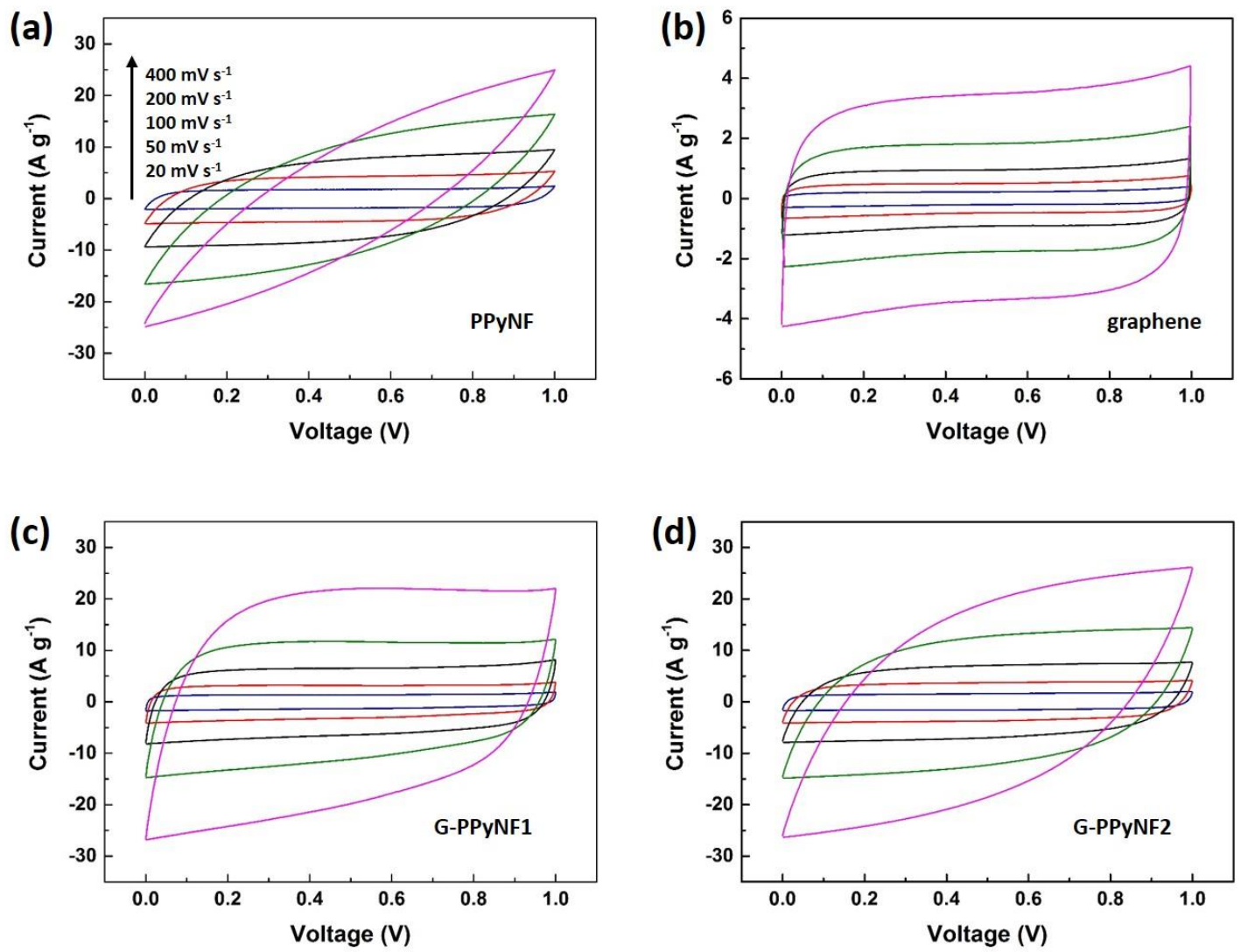

Figure 6. CVs of PPyNF (a), graphene (b), G-PPyNF1 (c), and G-PPyNF2 (d) electrodes in 1 $\mathrm{M} \mathrm{Li}_{2} \mathrm{SO}_{4}$.

Both PPyNF and G-PPyNF film electrodes displayed linear or quasi-linear charge/discharge curves under a relatively low current rate of $0.5 \mathrm{~A} \mathrm{~g}^{-1}$ (Figure 7), suggesting their good capacitive performance. Graphene delivered very low capacitance of $20 \mathrm{~F} \mathrm{~g}^{-1}$ at 1 $\mathrm{A} \mathrm{g}^{-1}$. In contrast, PPyNF film and G-PPyNF2 film electrode displayed a higher capacitance (152 $\mathrm{F} \mathrm{g} \mathrm{g}^{-1}, 156 \mathrm{~F} \mathrm{~g}^{-1}$ respectively), while G-PPyNF1 film offered a slightly lower capacitance of $130 \mathrm{~F} \mathrm{~g} \mathrm{~g}^{-1}$ due to the increased graphene content. PPyNF film electrode presented a poor rate performance with a decreased capacitance $\left(120 \mathrm{~F} \mathrm{~g}^{-1}\right)$ at $4 \mathrm{~A} \mathrm{~g}^{-1}$, only $80 \%$ of the value obtained at $1 \mathrm{~A} \mathrm{~g}^{-1}$; which can be ascribed to the limited conductivity. Due to the low capacitance, the performance of graphene film at higher current densities was not further studied. The introduction of graphene sheets could effectively increase the conductivity, thus 
render the composite electrode G-PPyNF1 and G-PPyNF2 with better rate performance. The G-PPyNF1 and G-PPyNF2 film maintained $98 \%$ and $91 \%$ of the initial capacitance when the current increased from $1 \mathrm{~A} \mathrm{~g} \mathrm{~g}^{-1}$ to $4 \mathrm{~A} \mathrm{~g}^{-1}$. The performance of this G-PPyNF film electrode was comparable to that of graphene/polypyrrole fibre composite electrode using graphene via conventional exfoliation of graphite oxide (132.9 to $170 \mathrm{~F} \mathrm{~g} \mathrm{~g}^{-1}$ under the similar/higher current rate) ${ }^{42,49-51}$. To be pointed out, it is the first report to use graphene from a surfactant assisted exfoliation process to produce flexible electrodes for supercapacitors. This work may provide additional avenues for development of flexible graphene-based electrodes. Nonetheless, the performance of this graphene/PPyNF film may be further improved by optimising the exfoliation process and the following synthesis procedure of polypyrrole fiber. 

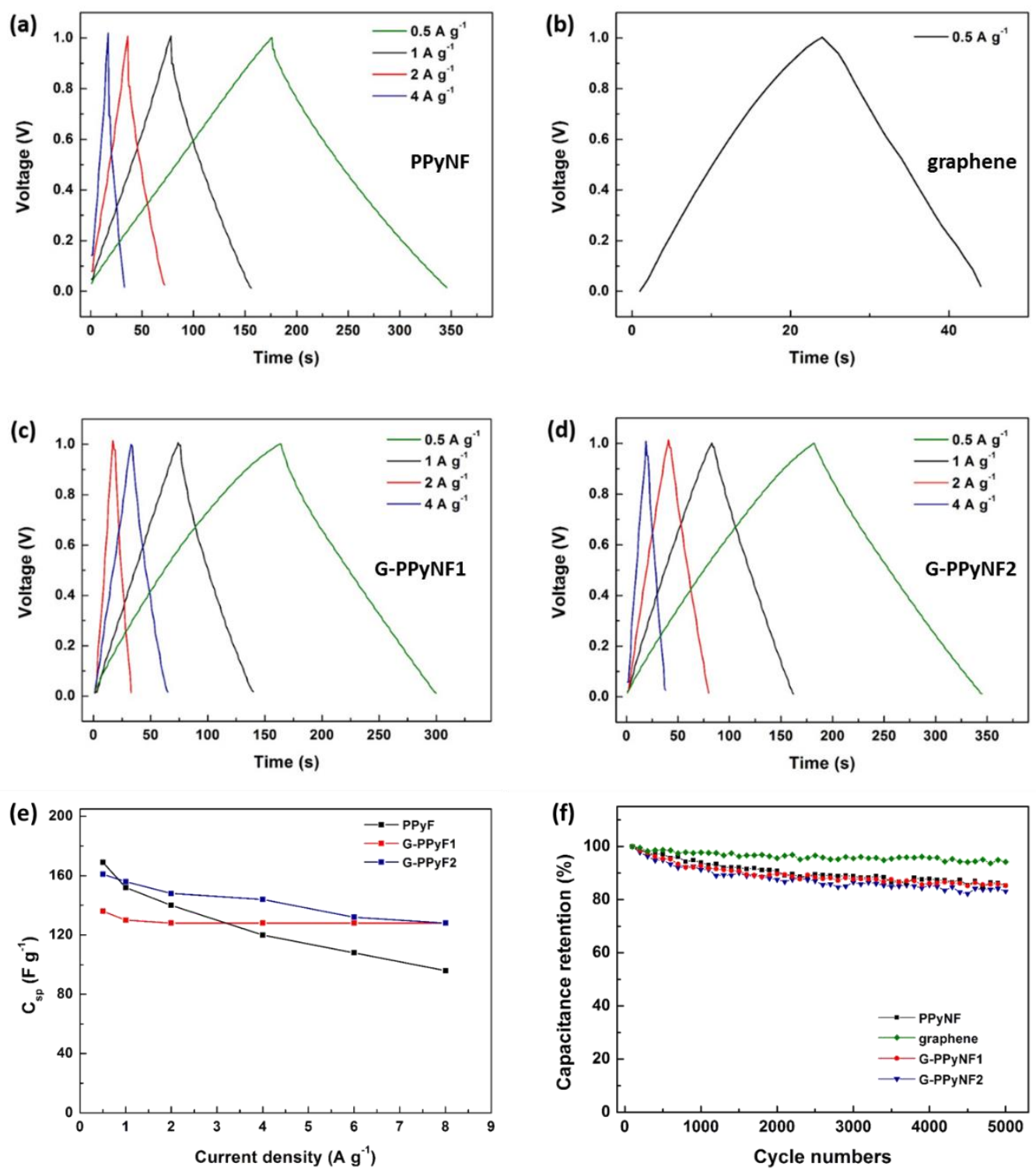

Figure 7. Charge/discharge curves of PPyNF (a), graphene (b), G-PPyNF1 (c) and GPPyNF2 film (d) in $1 \mathrm{M} \mathrm{Li}_{2} \mathrm{SO}_{4}$; Rate performance (e) and cycle stability (f) of graphene, PPyNF and G-PPyNF film electrodes.

The rate performance of G-PPyNF and PPyNF electrodes were compared using the galvanostatic charge/discharge results (Figure 7e). The G-PPyNF1 film with higher graphene content shows the best rate capability. When the current density increased from 0.5 to $8 \mathrm{~A} \mathrm{~g}^{-1}$, the capacitance retention was significantly improved to $94 \%$ (136 to $128 \mathrm{~F} \mathrm{~g}^{-1}$ ), much higher than that $56 \%$ (169 to $\left.96 \mathrm{~F} \mathrm{~g}^{-1}\right)$ for PPyNF film and 80\% (161 to $\left.128 \mathrm{~F} \mathrm{~g}^{-1}\right)$ for G-PPyNF2 
film. The cycle stability was tested by cyclic voltammetry at a scan rate of $100 \mathrm{mV} \mathrm{s}^{-1}$ for 5,000 cycles (Figure 7f). The G-PPyNF1 and G-PPyNF2 film maintained a capacitance retention rate of $85 \%$ and $83 \%$. The capacitance decay of PPy was mainly caused by the structural damage related to the doping/de-doping of ions during cycling ${ }^{52}$. The capacitance retention rate of our G-PPyNF films after 5,000 cycles can be up to $80 \%$, comparable to or higher than 50 87\% retention of the previously reported PPy based flexible electrodes $25,30,53$.

The Nyquist plots of PPyNF and G-PPyNF films are shown in Figure 8a. Two types of equivalent circuits are proposed based on their electrochemical process. For those film electrodes containing PPyNF, the equivalent circuit includes three resistors, two capacitive elements and one Warburg elements. The resistance elements include solution resistance $R_{\mathbb{s}}$, electron transfer resistance $\mathrm{R}_{\mathrm{ct}}$ and double layer resistance $\mathrm{R}_{\mathrm{dl}}$. Constant phase elements $\mathrm{CPE}_{\mathrm{f}}$ and $\mathrm{CPE}_{\mathrm{dl}}$ represent faradic pseudocapacitance and double layer capacitance, respectively. Warburg element $Z_{\mathrm{w}}$ reflects the ion diffusion process within electrodes. The equivalent circuit for graphene film doesn't contain the elements of $R_{c t}$ and $\mathrm{CPE}_{f}$ related to the pseudocapacitive redox reaction. The internal resistance, usually named equivalent series resistance (ESR), can be calculated from the intercept of the semi-circle with the real impedance axis. The ESR of graphene and G-PPyNF1 were $\sim 12 \Omega$, lower than that of GPPyNF2 (18 $\Omega$ ) and PPyNF (27 $\Omega$ ). The frequency response, which is plotted by the imaginary part of capacitance $\left(\mathrm{C}_{\mathrm{Im}}\right)$ against frequency, reflects the relative ion-transport rate within the electrode (Figure $8 \mathrm{~b}$ ). In the plot, the reciprocal of peak frequency is defined as relaxation time constant $\tau_{0}$, which describes the minimum time needed to discharge $50 \%$ of the energy stored in device ${ }^{54}$. A smaller $\tau_{0}$ reflects a better frequency response of the electrode, indicating better rate performance. The relaxation time constant for graphene, GPPyNF1, G-PPyNF2 and PPyNF film was $0.16 \mathrm{~s}, 1.2 \mathrm{~s}, 4.0 \mathrm{~s}$ and $12.6 \mathrm{~s}$, which matches well with the results of rate capability. The G-PPyNF1 film offered lower time constant compared 
to most of the previously reported graphene paper based supercapacitors ( 0.92 to $2.27 \mathrm{~s}),{ }^{55}$ and comparable to that of commercial available carbon based supercapacitors $(0.7 \text { to } 1.5 \mathrm{~s})^{56}$.
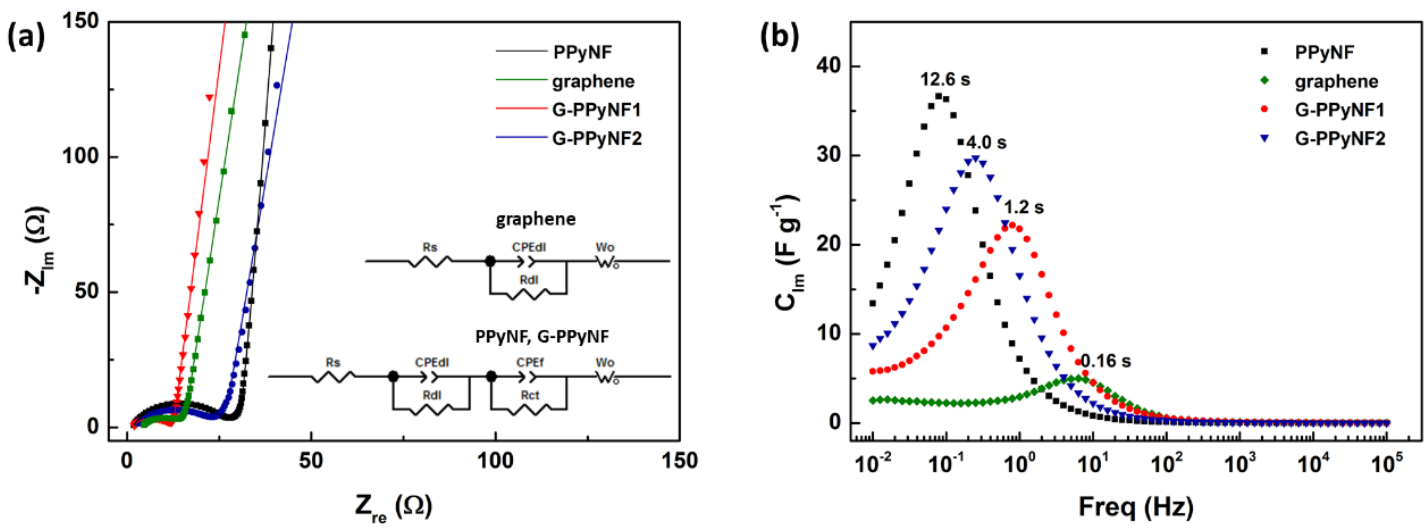

Figure 8. Nyquist plots (a) and frequency response (b) of graphene, PPyNF and G-PPyNF film electrodes. (inset of a) proposed equivalent circuit.

Considering the offered capacitance, we chose G-PPyNF2 hybrid film to investigate its flexibility and robustness. These films were bent to an angle of $180^{\circ}$ for up to 5,000 cycles (Figure 9a), and then assembled into supercapacitors for testing the electrochemical properties. The supercapacitor composed of films after the bending cycles demonstrated almost overlapped cyclic voltammograms with those pristine films (Figure 9b), indicating the bending has little impact. The well-maintained triangular shape of charge/discharge curves after bending test (Figure 9c) also evidences the good capacitive performance and robustness of this hybrid film. More specifically, $92 \%$ of the initial capacitance can be retained even after 5,000 bending cycles. To investigate the stability of this film at a charged sate, the selfdischarge profile of a fully charged supercapacitor composed of G-PPyNF2 films was investigated after it was charged to $1 \mathrm{~V}$ at a current density of $0.5 \mathrm{~A} \mathrm{~g}^{-1}$, and then held at this voltage for $2 \mathrm{~h}$ as reported. ${ }^{57}$ The open-circuit voltage dropped to $0.8 \mathrm{~V}$ after resting for $1.2 \mathrm{~h}$, 0.6 V after $5.7 \mathrm{~h}$, and $0.5 \mathrm{~V}$ (half of $\mathrm{Vmax}$ ) after $15.5 \mathrm{~h}$ (Figure 9d). Most supercapacitors are operated over a range of $\mathrm{V}_{\mathrm{Max}}$ to approximately half of $\mathrm{V}_{\mathrm{Max}}{ }^{58}$ Our device demonstrates a 
longer operable time compared to that $13 \mathrm{~h}, 6.7 \mathrm{~h}$ reported for flexible supercapacitors ${ }^{59-60}$, and $8 \mathrm{~h}$ of commercial available supercapacitor ${ }^{60}$. It also means that this flexible hybrid electrode can hold the charge for long periods of time.

(a)

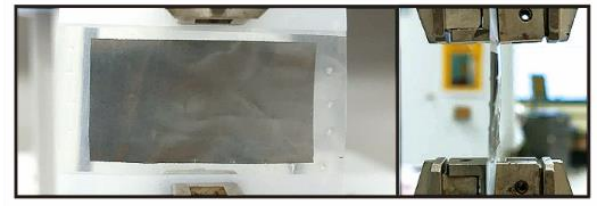

Bending angle $0^{\circ}$

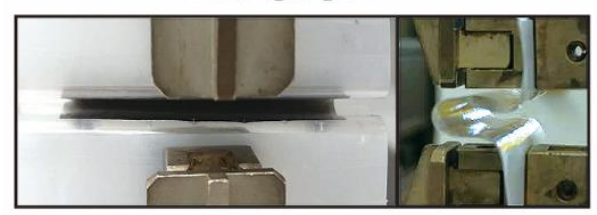

Bending angle $180^{\circ}$
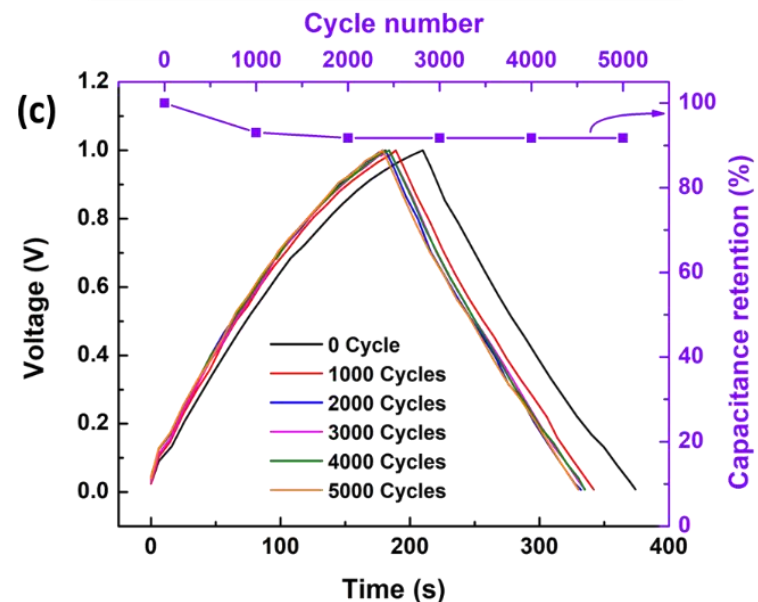

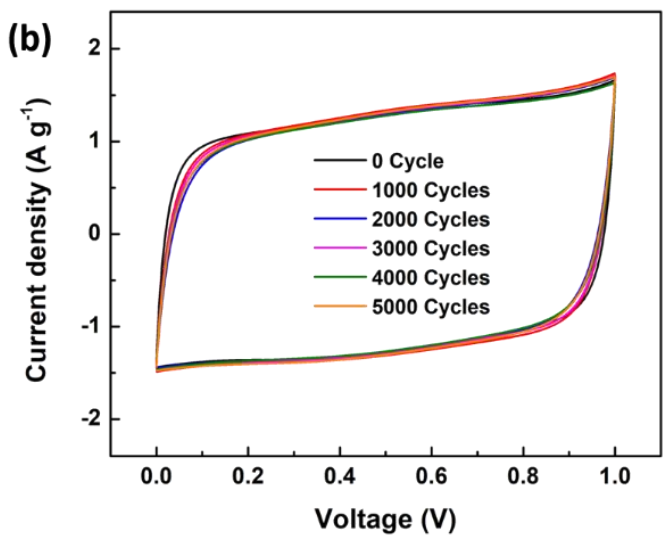

(d)

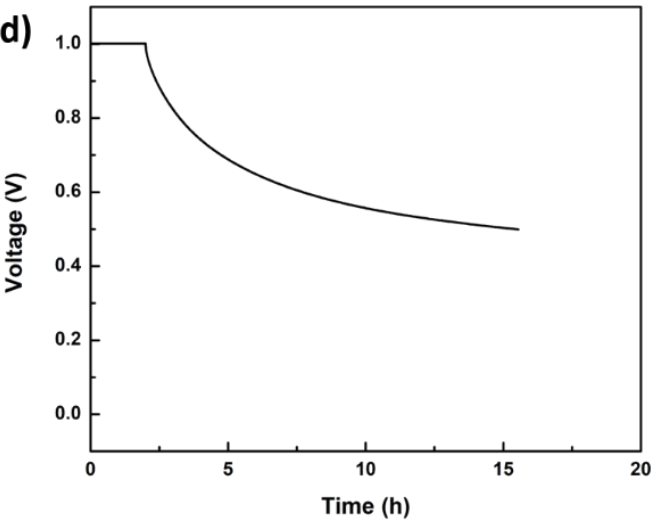

Figure 9. (a) Digital images of the bending test; Cyclic voltammograms at a scan rate of 20 $\mathrm{mV} \mathrm{s}^{-1}$ (b), charge/discharge curves and the capacitance retention at a current density of 0.5 $\mathrm{A}^{-1}$ (c) of a supercapacitor composed of G-PPyNF2 film electrodes after being subject to different bending cycles; (d) Open circuit voltage of a fully charged supercapacitor using GPPyNF2 film electrodes over time.

\section{CONCLUSION}

In summary, a flexible free-standing graphene-PPy fibre film was fabricated using graphene sheets exfoliated from worm-like expanded graphite with the assistance of a surfactant (CTAB). Such type of graphene displays a less-defected structure. A "tandem" 
strategy is applied in this work by using the surfactant remained in the diseprsion directly as a template for polypyrrole nanofibre growth without removal. The incorporation of PPyNF into graphene film not only provides large capacitance, but also improves the mechanical properties by binding and entangling the graphene platelets. The less defect graphene can effectively improve the rate capability of PPyNF due to the high conductivity. The resultant synergistic effect enables that G-PPyNF composite film electrode demonstrated a much larger capacitance compared to pure graphene film, and an improved rate capability compared to PPyNF film. In addition to the supercapacitor application, such graphene/PPyNF film may find applications in other type of flexible energy storage devices (i.e. alkaline ion batteries, metal air batteries) owing to the electrochemical features derived from graphene and polypyrrole such as lithium/sodium storage capability and electrocatalytic activity to oxygen reduction reaction. ${ }^{45,53,61}$

\section{AUTHOR INFORMATION}

Author contributions

The manuscript was written through contributions of all authors. All authors have given approval to the final version of the manuscript. K. Shu, Y. Chao, C. Wang, G. Wallace and S. Chou conceived the idea of this manuscript, designed the experiment and wrote manuscript. T. Zheng characterized the graphene nanosheets using AFM. S. Gambhir synthesized the starting materials expanded graphite. G. Wallace and C. Wang supervised the study.

\section{Funding sources}

The project was funded by the Australian Research Council Centre of Excellence Scheme (Project Number CE 140100012) and the AIIM Gold Grant. 


\section{ACKNOWLEDGEMENTS}

The authors gratefully acknowledge the Australian Research Council (ARC) for financial support under the ARC Centre of Excellence for Electromaterials Science (Project Number CE 140100012); the Australsian National Fabrication Facility-Materials node (ANFF) and UOW Electron Microscopy Centre for their provision of research facilities. C. Wang and S. Chou thank the financial support from AIIM Gold Grant. G. G. W. is grateful to the ARC for support under the Australian Laureate Fellowship scheme (FL110100196). K. Shu and Y. Chao acknowledge Chinese Scholarship Council (CSC) for their financial support during PhD studies.

\section{REFERENCES}

1. Geim, A. K., Graphene: Status and Prospects. Science 2009, 324 (5934), 1530-1534.

2. Novoselov, K. S.; Geim, A. K.; Morozov, S. V.; Jiang, D.; Zhang, Y.; Dubonos, S. V.; Grigorieva, I. V.; Firsov, A. A., Electric field effect in atomically thin carbon films. Science 2004, 306 (5696), 666-669.

3. Stoller, M. D.; Park, S.; Zhu, Y.; An, J.; Ruoff, R. S., Graphene-Based Ultracapacitors. Nano Letters 2008, 8 (10), 3498-3502.

4. Yoo, E.; Kim, J.; Hosono, E.; Zhou, H.-s.; Kudo, T.; Honma, I., Large Reversible Li Storage of Graphene Nanosheet Families for Use in Rechargeable Lithium Ion Batteries. Nano Letters 2008, 8 (8), 2277-2282.

5. Pang, C.; Lee, C.; Suh, K. Y., Recent Advances in Flexible Sensors for Wearable and Implantable Devices. Journal of Applied Polymer Science 2013, 130 (3), 1429-1441.

6. Bauer, S., Flexible Electronics: Sophisticated Skin. Nat Mater 2013, 12 (10), 871-872. 
7. Cheung, K. C.; Renaud, P.; Tanila, H.; Djupsund, K., Flexible Polyimide Microelectrode Array for In vivo Recordings and Current Source Density Analysis. Biosensors \& Bioelectronics 2007, 22 (8), 1783-1790.

8. Wang, C.; Wallace, G. G., Flexible Electrodes and Electrolytes for Energy Storage. Electrochimica Acta 2015, 175, 87-95.

9. Yang, C. Y.; Shen, J. L.; Wang, C. Y.; Fei, H. J.; Bao, H.; Wang, G. C., All-solidstate Asymmetric Supercapacitor Based on Reduced Graphene oxide/carbon nanotube and Carbon fiber paper/polypyrrole Electrodes. Journal of Materials Chemistry A 2014, 2 (5), $1458-1464$.

10. Wang, C.; Li, D.; Too, C. O.; Wallace, G. G., Electrochemical Properties of Graphene Paper Electrodes Used in Lithium Batteries. Chemistry of Materials 2009, 21 (13), 796-804.

11. Chen, H.; Müller, M. B.; Gilmore, K. J.; Wallace, G. G.; Li, D., Mechanically Strong, Electrically Conductive, and Biocompatible Graphene Paper. Advanced Materials 2008, 20 (18), 3557-3561.

12. Stankovich, S.; Piner, R. D.; Chen, X.; Wu, N.; Nguyen, S. T.; Ruoff, R. S., Stable Aqueous Dispersions of Graphitic Nanoplatelets via the Reduction of Exfoliated Graphite Oxide in the Presence of Poly(sodium 4-styrenesulfonate). Journal of Materials Chemistry 2006, $16(2), 155-158$.

13. Stankovich, S.; Dikin, D. A.; Piner, R. D.; Kohlhaas, K. A.; Kleinhammes, A.; Jia, Y.; Wu, Y.; Nguyen, S. T.; Ruoff, R. S., Synthesis of graphene-based nanosheets via chemical reduction of exfoliated graphite oxide. Carbon 2007, 45 (7), 1558-1565.

14. Hamilton, C. E.; Lomeda, J. R.; Sun, Z.; Tour, J. M.; Barron, A. R., High-Yield Organic Dispersions of Unfunctionalized Graphene. Nano Letters 2009, 9 (10), 3460-3462.

15. Lotya, M.; Hernandez, Y.; King, P. J.; Smith, R. J.; Nicolosi, V.; Karlsson, L. S.; Blighe, F. M.; De, S.; Wang, Z.; McGovern, I. T.; Duesberg, G. S.; Coleman, J. N., Liquid 
Phase Production of Graphene by Exfoliation of Graphite in Surfactant/Water Solutions. Journal of the American Chemical Society 2009, 131 (10), 3611-3620.

16. Zhao, M.; Liu, P., Adsorption of Methylene Blue from Aqueous Solutions by Modified Expanded Graphite Powder. Desalination 2009, 249 (1), 331-336.

17. Toyoda, M.; Inagaki, M., Heavy Oil Sorption using Exfoliated Graphite: New Application of Exfoliated Graphite to Protect Heavy Oil Pollution. Carbon 2000, 38 (2), 199210.

18. Sar1, A.; Karaipekli, A., Thermal Conductivity and Latent Heat Thermal Energy Storage Characteristics of Paraffin/expanded Graphite Composite as Phase Change Material. Applied Thermal Engineering 2007, 27 (8-9), 1271-1277.

19. Bian, J.; Xiao, M.; Wang, S. J.; Lu, Y. X.; Meng, Y. Z., Novel Application of Thermally Expanded Graphite as the Support of Catalysts for Direct Synthesis of DMC from $\mathrm{CH}_{3} \mathrm{OH}$ and $\mathrm{CO}_{2}$. Journal of Colloid and Interface Science 2009, 334 (1), 50-57.

20. Zaleski, P. L.; Derwin, D. J.; Girkant, R. J., Method for Expanding Lamellar Forms of Graphite and Resultant Product. Google Patents: 2001.

21. Jalili, R.; Aboutalebi, S. H.; Esrafilzadeh, D.; Konstantinov, K.; Moulton, S. E.; Razal, J. M.; Wallace, G. G., Organic Solvent-Based Graphene Oxide Liquid Crystals: A Facile Route toward the Next Generation of Self-Assembled Layer-by-Layer Multifunctional 3D Architectures. ACS Nano 2013, 7 (5), 3981-3990.

22. Bang, G. S.; So, H.-M.; Lee, M. J.; Ahn, C. W., Preparation of Graphene with Few Defects using Expanded Graphite and Rose Bengal. Journal of Materials Chemistry 2012, 22 (11), 4806-4810.

23. Hao, R.; Qian, W.; Zhang, L.; Hou, Y., Aqueous Dispersions of TCNQ-anionstabilized Graphene Sheets. Chemical Communications 2008, (48), 6576-6578. 
24. Zhu, L.; Zhao, X.; Li, Y.; Yu, X.; Li, C.; Zhang, Q., High-quality Production of Graphene by Liquid-phase Exfoliation of Expanded Graphite. Materials Chemistry and Physics 2013, 137 (3), 984-990.

25. Li, S.; Zhao, C.; Shu, K.; Wang, C.; Guo, Z.; Wallace, G. G.; Liu, H., Mechanically strong high performance layered polypyrrole nano fibre/graphene film for flexible solid state supercapacitor. Carbon 2014, 79, 554-562.

26. Biswas, S.; Drzal, L. T., Multi layered Nanoarchitecture of Graphene Nanosheets and Polypyrrole Nanowires for High Performance Supercapacitor Electrodes. Chemistry of Materials 2010, 22 (20), 5667-5671.

27. Zhou, X.; Tang, J.; Yang, J.; Xie, J.; Huang, B., Seaweed-like Porous Carbon from the Decomposition of Polypyrrole Nanowires for Application in Lithium ion Batteries. Journal of Materials Chemistry A 2013, 1 (16), 5037-5044.

28. Fu, H.; Du, Z.-j.; Zou, W.; Li, H.-q.; Zhang, C., Carbon nanotube Reinforced Polypyrrole Nanowire Network as a High-performance Supercapacitor Electrode. Journal of Materials Chemistry A 2013, 1 (47), 14943-14950.

29. Li, S.; Shu, K.; Zhao, C.; Wang, C.; Guo, Z.; Wallace, G.; Liu, H. K., One-Step Synthesis of Graphene/Polypyrrole Nanofiber Composites as Cathode Material for a Biocompatible Zinc/Polymer Battery. ACS Applied Materials \& Interfaces 2014, 6 (19), 16679-16686.

30. Lu, X.; Dou, H.; Yuan, C.; Yang, S.; Hao, L.; Zhang, F.; Shen, L.; Zhang, L.; Zhang, X., Polypyrrole/carbon nanotube nanocomposite enhanced the electrochemical capacitance of flexible graphene film for supercapacitors. Journal of Power Sources 2012, 197 (Supplement C), 319-324. 
31. Shu, K.; Wang, C.; Wang, M.; Zhao, C.; Wallace, G. G., Graphene cryogel papers with enhanced mechanical strength for high performance lithium battery anodes. Journal of Materials Chemistry A 2014, 2 (5), 1325-1331.

32. Gu, W.; Zhang, W.; Li, X.; Zhu, H.; Wei, J.; Li, Z.; Shu, Q.; Wang, C.; Wang, K.; Shen, W.; Kang, F.; Wu, D., Graphene Sheets from Worm-like Exfoliated Graphite. Journal of Materials Chemistry 2009, 19 (21), 3367-3369.

33. Jiang, B.; Tian, C.; Wang, L.; Xu, Y.; Wang, R.; Qiao, Y.; Ma, Y.; Fu, H., Facile Fabrication of High Quality Graphene from Expandable Graphite: Simultaneous Exfoliation and Reduction. Chemical Communications 2010, 46 (27), 4920-4922.

34. Tuinstra, F.; Koenig, J. L., Raman Spectrum of Graphite. The Journal of Chemical Physics 1970, 53 (3), 1126-1130.

35. Wall, M., Raman Spectroscopy Optimizes Graphene Characterization. Advanced Materials \& Processes 2012, 170 (4), 35-38.

36. Ferrari, A. C.; Meyer, J. C.; Scardaci, V.; Casiraghi, C.; Lazzeri, M.; Mauri, F.; Piscanec, S.; Jiang, D.; Novoselov, K. S.; Roth, S.; Geim, A. K., Raman Spectrum of Graphene and Graphene Layers. Physical Review Letters 2006, 97 (18), 187401.

37. Malard, L. M.; Pimenta, M. A.; Dresselhaus, G.; Dresselhaus, M. S., Raman Spectroscopy in Graphene. Physics Reports 2009, 473 (5-6), 51-87.

38. Vadukumpully, S.; Paul, J.; Valiyaveettil, S., Cationic surfactant mediated exfoliation of graphite into graphene flakes. Carbon 2009, 47 (14), 3288-3294.

39. Yang, D.; Velamakanni, A.; Bozoklu, G.; Park, S.; Stoller, M.; Piner, R. D.; Stankovich, S.; Jung, I.; Field, D. A.; Ventrice Jr, C. A.; Ruoff, R. S., Chemical Analysis of Graphene Oxide Films after Heat and Chemical Treatments by X-ray Photoelectron and Micro-Raman Spectroscopy. Carbon 2009, 47 (1), 145-152. 
40. Ganguly, A.; Sharma, S.; Papakonstantinou, P.; Hamilton, J., Probing the Thermal Deoxygenation of Graphene Oxide Using High-Resolution In Situ X-ray-Based Spectroscopies. The Journal of Physical Chemistry C 2011, 115 (34), 17009-17019.

41. Tietze, L. F.; Beifuss, U., Sequential Transformations in Organic Chemistry: A Synthetic Strategy with a Future. Angewandte Chemie International Edition in English 1993, $32(2), 131-163$.

42. Zhang, X.; Zhang, J.; Liu, Z.; Robinson, C., Inorganic/organic Mesostructure Directed Synthesis of Wire/ribbon-like Polypyrrole Nanostructures. Chemical Communications 2004, (16), 1852-1853.

43. Han, Y.; Qing, X.; Ye, S.; Lu, Y., Conducting polypyrrole with nanoscale hierarchical structure. Synthetic Metals 2010, 160 (11), 1159-1166.

44. Zhang, X.; Zhang, J.; Song, W.; Liu, Z., Controllable Synthesis of Conducting Polypyrrole Nanostructures. The Journal of Physical Chemistry B 2006, 110 (3), 1158-1165.

45. Yang, Y.; Wang, C.; Yue, B.; Gambhir, S.; Too, C. O.; Wallace, G. G., Electrochemically Synthesized Polypyrrole/Graphene Composite Film for Lithium Batteries. Advanced Energy Materials 2012, 2 (2), 266-272.

46. Cassignol, C.; Olivier, P.; Ricard, A., Influence of the dopant on the polypyrrole moisture content: Effects on conductivity and thermal stability. Journal of Applied Polymer Science 1998, $70(8), 1567-1577$.

47. Omastová, M.; Trchová, M.; Kovářová, J.; Stejskal, J., Synthesis and Structural Study of Polypyrroles Prepared in the Presence of Surfactants. Synthetic Metals 2003, 138 (3), 447455.

48. Mao, L.; Chan, H. S. O.; Wu, J., Cetyltrimethylammonium Bromide Intercalated Graphene/polypyrrole Nanowire Composites for High Performance Supercapacitor Electrode. RSC Advances 2012, 2 (28), 10610-10617. 
49. Xu, C.; Sun, J.; Gao, L., Synthesis of novel hierarchical graphene/polypyrrole nanosheet composites and their superior electrochemical performance. Journal of Materials Chemistry 2011, 21 (30), 11253-11258.

50. Sahoo, S.; Dhibar, S.; Hatui, G.; Bhattacharya, P.; Das, C. K., Graphene/polypyrrole nanofiber nanocomposite as electrode material for electrochemical supercapacitor. Polymer 2013, 54 (3), 1033-1042.

51. Ye, S.; Feng, J., Self-Assembled Three-Dimensional Hierarchical Graphene/Polypyrrole Nanotube Hybrid Aerogel and Its Application for Supercapacitors. ACS Applied Materials \& Interfaces 2014, 6 (12), 9671-9679.

52. Zhang, J.; Zhao, X. S., Conducting Polymers Directly Coated on Reduced Graphene Oxide Sheets as High-Performance Supercapacitor Electrodes. The Journal of Physical Chemistry C 2012, 116 (9), 5420-5426.

53. Cui, Y. M.; Wen, Z. Y.; Liang, X.; Lu, Y.; Jin, J.; Wu, M. F.; Wu, X. W., A tubular polypyrrole based air electrode with improved O-2 diffusivity for Li-O-2 batteries. Energy \& Environmental Science 2012, 5 (7), 7893-7897.

54. Taberna, P. L.; Simon, P.; Fauvarque , J. F., Electrochemical Characteristics and Impedance Spectroscopy Studies of Carbon-Carbon Supercapacitors. Journal of The Electrochemical Society 2003, 150 (3), A292-A300.

55. Zhu, J.; Cheng, C.; Yang, X.; Wang, Y.; Qiu, L.; Li, D., Dynamic Electrosorption Analysis as an Effective Means to Characterise the Structure of Bulk Graphene Assemblies. Chemistry - A European Journal 2013, 19 (9), 3082-3089.

56. Zhang, S.; Pan, N., Supercapacitors Performance Evaluation. Advanced Energy Materials 2015, 5 (6), 1401401. 
57. Kou, L.; Huang, T.; Zheng, B.; Han, Y.; Zhao, X.; Gopalsamy, K.; Sun, H.; Gao, C., Coaxial wet-spun yarn supercapacitors for high-energy density and safe wearable electronics. Nature communications 2014, 5, 3754.

58. Stoller, M. D.; Ruoff, R. S., Best practice methods for determining an electrode material's performance for ultracapacitors. Energy \& Environmental Science 2010, 3 (9), $1294-1301$

59. Zheng, L.; Chang, Y.; Xiaoming, F.; Shaohong, L.; Juan, Y.; Mengdi, Z.; Gang, W.; Nan, X.; Jieshan, Q., Freeze-drying for sustainable synthesis of nitrogen doped porous carbon cryogel with enhanced supercapacitor and lithium ion storage performance. Nanotechnology 2015, $26(37), 374003$.

60. El-Kady, M. F.; Kaner, R. B., Scalable fabrication of high-power graphene microsupercapacitors for flexible and on-chip energy storage. Nature Communications 2013, 4, 1475.

61. Kong, Y.; Wang, C.; Yang, Y.; Too, C. O.; Wallace, G. G., A battery composed of a polypyrrole cathode and a magnesium alloy anode-Toward a bioelectric battery. Synthetic Metals 2012, 162 (7), 584-589. 
Table of Contents Graphic

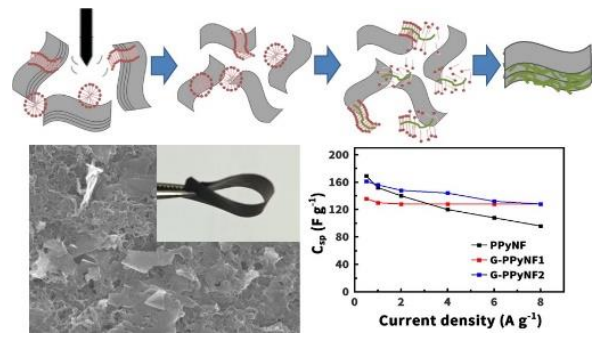

